\title{
La escritura de "Valle de Elqui", de Poema de Chile: Pliegue recuerdo-naturaleza
}

The writing of "Elqui Valley" from Poem of Chile: The memory-naturefold

\section{Vilma Muñoz Iturra}

Universidad de Concepción, Chile

E-mail: vilmunoz@udec.d

\section{RESUMEN}

En Poema de Chile de Gabriela M istral se produce una casa neobarroca. En la sección "Valle de Elqui", esta producción está dada por pliegues de pensamiento - pliegues de memoria-, que permiten a la mónada Gabriela aprehender el afuera y hacer de éste una forma de interioridad donde puede resistir la vejez, el exilio, la muerte.

Palabras claves: Poema de Chile, Mistral, pliegues, neobarroco.

\section{ABSTRACT}

A N eobaroquehouseisproduced in Gabriela M istral's Poem of C hile. In the section "Elqui Valle" this production is given by folds of thinking - folds of memory-, that enable G abrielamonad to apprehend the outside and turn it into a kind of interiority where old age, exile and death can be endured.

Keywords: Poema de Chile, Mistral, folds, neobaroque.

Recibido: 25-04-2006. Aceptado: 28-08-2006.

DEM A de Chile de Gabriela M istral se puede abordar como una casa neobarroca, en donde lo fundamental es el pliegue y el replieguel. En este artículo daremos cuenta de su producción y funcionamiento; para ello nos si-

${ }^{1}$ Este concepto lo derivamos del concepto deleuziano de casa barroca, categoría filosófica que da cuenta de la armonía entre la mónada y el cuerpo. El concepto de casa neobarroca se aplica a la escritura para designar, por una parte, la relación que hay entreel escritor, en tanto quemónada, y su 
tuaremos en uno de los apartados del libro, el denominado "Valle de Elqui", de acuerdo con la edición de 1997 de Jaime Q uezada, apartado que contiene poe mas que hablan sobre dicho lugar geográfico. C reemos que este apartado constituye el eje de las reflexiones que $M$ istral formuló durante toda su vida literaria y en particular en su vejez, en el que se hace notoria la coincidencia entre el sujeto textual y el sujeto biográfico². En "Valle de Elqui", la mónada hace sus pliegues por medio de los pensamientos, de los recuerdos, que capturan imáge nes del Valle de Elqui y permiten aprehender el afuera, hacer del afuera una forma de interioridad ${ }^{3}$. A su vez, este afuera, que ya ha pasado a constituir una interioridad, una subjetividad, queda registrado en un repliegue de materiaescritura. Casa neobarroca, conexión entre pliegue-mónada y repliegue escritu$\mathrm{ra}$, intercomunicación entre ambos departamentos, necesidad del uno para efectuar el otro, escritura de resistencia, diario de vida.

¿Cómo crear bloques de vida-luz cuando se está pasando por la vejez, por una oscuridad que sólo es comprendida como parcial, porque va a adquirir una nueva forma que luego, a su vez, se va a deshacer en otra? Es ahí donde creemos que ingresa un recuerdo sobre el Valle de Elqui, que nada tiene que ver con la territorialización, con lo edípico, con lo maternal. Se escribe "con bloques de infancia" y se hace un pliegue con el recuerdo, que en este caso es una manifestación del afuera, un afuera que puede ser las fuerzas de las curvas delas monta-

escritura, en tanto que materia, cuerpo, por donde se filtra el afuera. El calificativo de neobarroco sitúa la casa ya no en la época del Barroco propiamente tal, sino en la época actual, tomando de barroco su procedimiento: el pliegueal infinito. Por otra parte, la partícula "neo" designaría un plus un agregado a estos pliegues: serie de elementos incomposibles entre sí. Lo que implicaría que la mónada, no obstante su hermetismo, da cabida a una fisura en el piso de arriba: está semiabierta a los flujos del afuera y los de otras mónadas.

2 La coincidencia, en Poema de Chile, entre el sujeto textual y el biográfico ha sido uno de los aspectos más señalados por la crítica literaria; baste con indicar que Santiago D aydí-Tolson muestra que en el texto hay varios procedimientos que permiten constatar que el sujeto de la enunciación (fantasma o "mama”) se corresponde con el autor biográfico. Algunos de los artículos en que se alude ala concordancia entresujeto textual-sujeto biográfico son: "Gabriela M istral y su Poema deC hile" (1969), "El yo lírico en Poema deChile de Gabriela M istral" (1982) y "Las patrias de G abriela M istral" (1986).

El concepto de afuera lo extraemos de $D$ eleuze y nos atenemos al uso y definición queél hace de acuerdo con su interpretación y glosa delos textos de Foucault. Es así que entendemos por afuera una fuerza que actúa en relación con otra fuerza. El afuera difiere dela exterioridad, por cuanto éste último concepto corresponde a una forma; pero "el afuera concierne a la fuerza: si la fuerza siempre está en relación con otras fuerzas, las fuerzas remiten necesariamente a un afuera irreductible, que ya ni siquiera tiene formas, que está hecho de distancias indescomponibles gracias a las cuales una fuerza actúa sobre otra o actúa sobre ella. Una fuerza siempre contiene a otras, desde afuera, es afectación variable que sólo existeatal distancia o bajo tal relacion" (D eleuze, 1987: 115). A su vez, "lasfuerzas en e hombre entran en relación con fuerzas de elevación al infinito. Estas son claramente las fuerzas de afuera, puesto que el hombre es limitado y no puede explicar esa potencia más perfecta que lo atraviesa" (D eleuze, 1987: 160). 
ñas, de los árboles naciendo en hojas, de los pájaros danzando al viento, de las semillas germinando la tierra; pero que siempre arrancan al hombre hacia un más allá de su condición humana. Todo es movimiento de fuerzas y ese deseo avasallante de U n-andar-la-G ea4. Poema deChileno es sólo la descripción de un lugar geográfico y cultural (C hile), sino más bien el espacio literario en dondese colocan en funcionamiento bloques de sensaciones desencadenadas cuando se participa de esta tierra no como un sujeto, sino como un elemento más. Si decimos que Poema deC hile es un texto neobarroco no es tanto por su relación con el barroco español, en lo que concierne con la preponderancia de la figura de la elipsis, sino por su procedimiento fundamental, de acuerdo con Gilles D eleuze, el pliegue sobre pliegue. Si bien es cierto que la figura de la elipsis, con su procedimiento de esclarecer una cosa y ocultar otra, nos puede arrojar matices sobre el texto - al dejar entrever como lo iluminado el espacio chileno, su flora, fauna y geografía, mientras que como lo oscurecido la distancia física que mantiene el hablante en relación con el espacio del que habla- creemos, no obstante, que este procedimiento estanca nuestra lectura si no nos situamos precisamente en ese espacio que hay entrel o focalizado y lo que escapa al centro. D e esta manera, la distancia del sujeto textual en relación con el espacio físico chileno no hace más que revelar su soporte: escritura. ¿Pero en qué medida esta escritura es vital? No es por el camino de la ficcionalización de una realidad chilena en donde encontraremos una respuesta satisfactoria, sino en aquellos componentes políticos que se despliegan en esta escritura mistraliana. M istral traza una línea de fuga allí donde no está la salida. Si no se puede regresar físicamente a Chile, entonces el viaje tendrá que ser en intensidad; a las fuerzas que imponen una distancia física se le responde con una fuerza espiritual. Para ello utiliza un lenguaje arcaico 0 , como ella lo nombra, "hablando lengua, no otra, que la primitiva mía" (Q uezada, 2002: 48), ese lenguaje atravesado de conocimiento narrativo: "Séde plantas casi tanto como deliteratura" (Q uezada, 2002: 186), que le permite participar de esas fuerzas vital es que vislumbró en el Valle de Elqui. M istral construye su escritura de resistencia frente a la muerte y a su condición de extranjera por medio de un gran plieguedememoria. Entendemos como pliegue de memoria, de acuerdo con D eleuze, las micropercepciones del pensamiento que atraen al interior del ser el afuera, que transforman el afuera en una interioridad, de manera que por medio de los pliegues "lo más lejano devieneinterior al transformarse en lo máspróximo" (D eleuze, 1987:158). La memoria, el pliegue de la memoria, da cuenta del "afecto de sí por sí mismo"

${ }^{4}$ Utilizamos esta forma de expresión como el nombre propio de una haecceidad, según la terminología deleuziana. 
(D eleuze, 1987:158). Entendemos por memoria la absoluta memoria, de acuerdo con D eleuze, "que dobla el presente, que redobla el afuera, y quese identifica con el olvido, puesto que ella misma es sin cesar olvidada para ser rehecha" (D el euze, 1987:141). D esde esta perspectiva un pliegue de memoria es un plie gue de resistencia contra la muerte 0 el "olvido del olvido" ${ }^{\text {, }}$ que resiste al tiempo porque expande el pasado al presente y resiste al presente al llenarlo de un futuro (Cfr. D eleuze, 1987: 155).

Ahora bien, el primer poema que abre la sección Valle de Elqui, se titula de igual forma y en él se describe el regreso de M istral "con cabellos cenicientos" a dicha tierra. Es un poema, según nuestra percepción, con una fuerza mayor 0 por lo menos distinta de la gran mayoría de los otros poemas. Se nos hace evidente una gran inclinación de la mónada. Ya nos decía Leibniz, según D eleuze, que cada individuo expresa del mundo aquella parte que es más afín con sus singularidades. M istral se encargó en múltiples textos de reafirmarnos esto: “EI mar me gusta mucho menos que la montaña. (...) La montaña me lo da todo. $M$ e eleva el alma intensamente, me aplaca y me vivifica. En cada quebrada con sombra pongo genios de la tierra, poderes, prodigios. (...) Todos los colores de mi montaña me gustan" (Q uezada, 2002: 23). El poema se inicia diciendo:

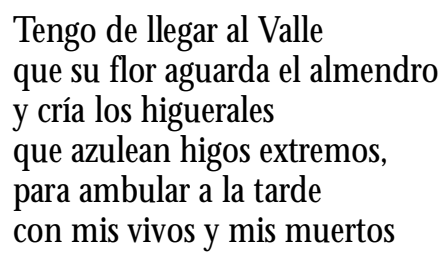

(M istral, 1997: 65)

D estaca en la estrofa anterior la conexión de elementos que se contradicen entre sí: el andar (ambular) la tarde. Se crea un percepto temporal: "el andar la tarde" quesitúa el poema en la problemática del tiempo. Esun texto quecorresponde a una poesía dialéctica, si seguimos la denominación de D ieter 0 elker, por cuanto secaracteriza "por ir construyendo su sentido a partir de la recurrencia de voces discrepantes" (0 elker, 1989: 98), que coloca en evidencia "la conciencia de finitud y voluntad de infinito" (0 elker, 1989: 103). En el texto, el mecanismo que permite que el sujeto se agencie con un tiempo infinito o eterno es la memoria, la que trae el pasado al presente. Lo anterior hace posible la producción en el texto demundosincomposibles entresí: "el mundo delos vivos" y "el mundo de los muertos".

\footnotetext{
${ }^{5}$ Terminología empleada por D eleuze (C fr. D eleuze, 1987: 141).
} 
En este poema, $M$ istral reúne a todo lo querido "de los que se aman sin tiempo / y mudossehablan sin más / que la sangrey los alientos" (M istral, 1997: 65) en un gran despliegue de memoria, donde se pasa a un mundo composible que ya no difiere con el mundo del presente de la enunciación, sino que el momento en el que se emite esos enunciados se carga de un presente eterno, en el que las series de acontecimientos ya no divergen: necesidad de pensar, plegar, recordar todo sin tiempo para vivir Un Valle, una haecceidad naturaleza, porque todo lo queingrese es naturaleza o seagencia con ella. Luego el poema dice:

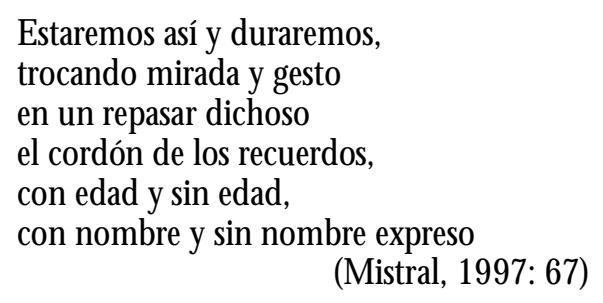

“N osotros repasaremos el cordón de los recuerdos", habrá pliegues que irán de una mónada a otra, mónadas semiabiertas que reciben los influjos del exterior, pero que ya están plegados en un adentro de las almas. Las series de acontecimientos ya no serán divergentes si se participa de ese mundo otro, singularidades distintas, pero que pertenecen a una misma tribu a fuerza del mismo afecto:

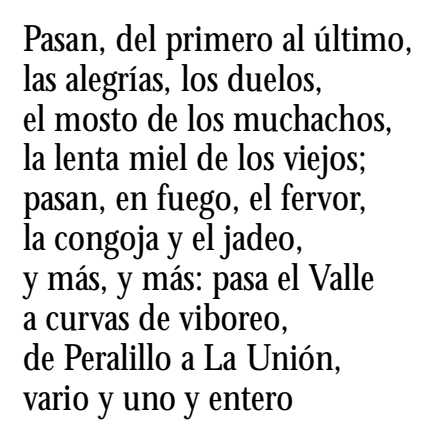

(M istral, 1997:67)

El lenguaje se hace delocutivo, tal vez, para señalar las fuerzas que pasan ya por $M$ istral, ya por ese nosotrosanterior, un afuera manifestándose en cada uno, fuerza impersonal izada que atraviesa todo como un torrente. $Y$ entre todas esas fuerzas la posibilidad de enunciar un gran despliegue de la mónada: "el Valle a curvas de viboreo". Pliegue sobre pliegues para trazar esa macropercepción, per- 
cepción clara, consciente y nítida sobreel Valle de Elqui, para traerles "Ia lengua y los gestos que me dieron". Luego dice:

\author{
M i infancia aquí mana leche \\ de cada rama que quiebro \\ y de mi cara se acuerdan \\ salvia con el romero \\ y vuelven sus ojos dulces \\ como con entendimientos
}

(M istral, 1997: 67)

"Se escribe con bloques de infancia", dice D eleuze. A lo que M istral respondería: "Escribiendo, o viviendo, las imágenes nuevas que me nacen siempre sobre el subsuelo de la infancia. Sigo usando sonidos, visiones y hasta olores de infancia" (Q uezada, 2002: 245). H acer de la infancia un gran pliegue, conectar ese pliegue con uno de naturaleza, son dos flujos que en $\mathrm{M}$ istral nunca se han contradicho, puesto que siempre han sido flujos de vida. En el fragmento anteriormente citado, la percepción clara es la de la salvia y el romero; se da una comunicación con la flora, M istral se agencia con la flora. Ahora bien, en el poema "A veces, mama, te digo" - del apartado ValledeElqui-, el sujeto textual niño diaguita cuestiona esta práctica y le dice a la mujer fantasma (M istral): "hablas lo mismo que el loco", a lo que ella responde, refiriéndose a la naturaleza: "Porque todos están vivos/ y a los vivos les respondo" (M istral, 1997: 69). D e esta manera, quizás, tanto en la estructura interna de Poema de Chile -a través del destinatario directo niño-diaguita-, como en la externa - por medio de los lectores-, se desprende ese intento de mostrar un afuera naturaleza.

A continuación citamos un fragmento del poema "Tordos":

$$
\begin{aligned}
& \text { A estas horas y lo mismo } \\
& \text { que cuando yo era chiquilla } \\
& \text { y me hablaban de tú a tú } \\
& \text { el higueral y la viña } \\
& \text { están cantando embriagados } \\
& \text { de la estación más bendita } \\
& \text { los tordos de M ontegrande } \\
& \text { y cantan a otra Lucila } \\
& \text { (...) } \\
& \text { Yo me tengo lo perdido } \\
& \text { y voy llevando mi infancia }
\end{aligned}
$$

\footnotetext{
${ }^{6} \mathrm{El}$ destacado es nuestro.
} 


\author{
como una flor preferida \\ que me perfuma la mano. \\ Y la madre va conmigo \\ sol a sol y día a día \\ va con rostro y va sin Ilanto \\ cantándome los caminos
}

(M istral, 1997: 80)

En el fragmento anterior se hace explícito que Gabriela M istral se reconoce como sujeto textual y biográfico de Poema de C hile. Para ello ingresa su nombre civil, provocando una comunicación entre su obra y su vida. D e esta manera, lo que aparece en la escritura da cuenta de un pliegue que hace su mónada y que queda registrado en un repliegue de escritura. El entrepliegue es, a su vez, la escritura que permite, para nosotros los lectores y para ella en su reconstrucción de un espacio chileno, no tan sólo dar cuenta de la comunicación que existe entre la aprehensión que hace esta mónada del afuera y su peculiar subjetividad o interioridad, sino también producir esa subjetividad de pensamiento, en la que trabajar un diario de vida es arrancarle a la vida flujos, hacer una recapitulación de lo vivido como procedimiento quedesencadena acciones futuras marcadas por dicha inclinación de la mónada. En estas estrofas se puede visualizar esa casa neobarroca, en la que se comunican las dimensiones subjetividad y materialidad, donde entran en comunión una serie de elementos, aprehensiones, caóticas tal vez, a fuerza de nacer del acto de recordar. C reemos queen Poema de Chile, y en este fragmento, el pliegue fundamental es el pensamiento, puesto que en el pensar se dobla el afuera "en un adentro coextensivo a él" (D eleuze, 1987: 154), en dondetoda percepción y aprehensión del mundo está relacionada con el espacio del afuera "independientemente de las distancias y en el límite de un viviente" (D eleuze, 1987: 154). D esde esta perspectiva, se escribe en el extranjero para producir una nueva casa, que no es tan sólo la materialidad de la escritura, sino, por sobre todo, los flujos que por ella pasan: flujos recuerdos cargados de presente, que a su vez dan cuenta de una inclinación futura del alma. Pero estepensar replegado en la materia (escritura), si ha de ser considerado una obra de arte, si hemos de situar Poema de Chile como un diario de vida literario, por sobre todo estético, debemos entonces enfatizar qué es lo que está pasando por ahí, por esa escritura experimental: un bloquedesensaciones; bloque que $D$ eleuze singulariza como perceptos y afectos.

Se aprecia cómo el pliegue de recuerdo, de pensamiento, aprehende de una manera universal, que sobrepasa a la mónada de $M$ istral, un bloque de sensaciones, en donde los perceptos son ese lenguaje no humano, sino telúrico, esa comunicación que en el pasado se hacía con loshigueralesy las viñas y que ahora, en el 
presente de la enunciación, se hace con los tordos La comunicación con los elementos de la naturaleza atrae hacia el interior de la mónada partículas de ésta, las que hacen a la mónada experimentar un devenir no humano, en el cual se participa de la tierra como un elemento más de ella. Serie de recuerdo higueras-viñas-M ontegrande conectadas o plegadas con la serie Tordos, repliegue de ella en el acto de escribir con bloques de infancia, donde la mónada conecta un espacio pasado con uno presente que se extiende, a su vez, a un futuro marcado por devenires vegetales y animales. Conexión, por otra parte, de la serie higueraviña-M ontegrande y Tordos con la seriemadre, y de ésta con la seriecanto, siendo todas ellas elementos aparentemente disonantes, pero armónicos en acordes de sensaciones presentes. Las series siguen en los otros poemas, son flujos que se entrecruzan, que armonizan y se expanden ad infinitum. Se participa del cantar delos tordos por medio del recuerdo, ya no el recuerdo que territorial iza, sino el quees flujo devida porque expandeel pasado a un presente en el que se vive ese afuera, el canto de los tordos, afuera que ya constituye una interioridad. El poema dice:

$$
\begin{aligned}
& \text { Pero con que yo me calle } \\
& \text { como el monte o la beguina } \\
& \text { el cantar del embriagado } \\
& \text { me al canza a la extranjería } \\
& \text { porque no me cuesta, no, } \\
& \text { recobrar canción perdida }
\end{aligned}
$$

(M istral, 1997: 79)

El cantar de los tordos lleno de embriaguez es experimentado por el hablante lírico por medio del recuerdo.

En otro poema, "Salto del Laja”, el sujeto textual/biográfico dice:

$$
\begin{aligned}
& \text { M e voy con el río Laja, } \\
& \text { me voy con las locas víboras, } \\
& \text { me voy por el cuerpo de Chile; } \\
& \text { doy vida y voluntad mías; } \\
& \text { juego sangre, juego sentidos } \\
& \text { y me entrego, ganada y perdida. }
\end{aligned}
$$

$$
\text { (M istral, 1997: 189) }
$$

En el fragmento anterior, la mónada aprehende el afuera, un afuera que es un acontecimiento: Río Laja. Gabriela reactualiza en su interior el flujo eterno del agua, participa de ese vector que es todo movimiento y velocidad. Pero participar del flujo agua no es participar de cualquier velocidad, puesto que 
entre la mónada y el fuera no hay mediación de prótesis tecnológicas', sino que la mónada crea su propia subjetividad, hace su propio acorde, y en la cual, entre la percepción y el objeto percibido, sólo hay pliegues de pensamiento.

Ser puro acontecimiento, producir acontecimientos es conectarse demanera nómade con la tierra. D esde esta perspectiva, y al relacionar las piezas de esta máquina nómade, percibimos porqué $G$ abriela no puede conectarse con las casas, porqué las esquiva: "es que me ahogan las casas / O ye tú, cuando las hacen / desperdician las montañas" (M istral, 1997: 145). Las casas territorializan, cortan los flujos, estrían el espacio, dificultan los devenires e impiden el participar de la tierra. Pero el nomadismo no se define por el movimiento, como podría pensarse, sino por la velocidad, por cuanto no tan sólo se puede viajar en intensidad (tal es el caso de G abriela M istral, que escribe en el extranjero, que produce en el extranjero una realidad chilena), sino más bien porque el habitar la tierra a condición de ser nómade implica saber que no hay movimiento, puesto que no existe un solo cuerpo, sino una multiplicidad, en la cual se es pieza del espacio liso. N omadismo en la escritura como última casa neobarroca donde la mónada Gabriela hace bloque con otras: mónada niño, mónada huemul. Las mónadas neobarrocas permanecen semiabiertas a fuerza de plegar flujos de otras mónadas. Se posee la tierra en potencia escritura, pero esta escritura no es una nueva territorialización como señala Soledad Falabella (1994), sino que al ser visualizado como diario de vida abre un flujo que permite que esta mónada libere percepciones conscientes, macropercepciones o un despliegue quesitúa la muerte en un espacio fluctuanteposible de leer para nosotros, también abiertos a una lectura-escritura experimental, como un proceso de recapitulación que salva lo inteligible en el desasirse de un cuerpo biológico para ser uno con la muerte. Blanchot señala sobre la relación escritura-muerte que "sólo se puede escribir cuando se es dueño de sí frente a la muerte y cuando se establecen con ella relaciones de soberanía (...) Q uien dispone de ella, dispone extremadamente de sí, está ligado a todo lo que puede, es integralmente poder" (Blanchot, 1969: 82-83). Entre los múltiples pliegues está ese elíptico que podemos reconstruir como un acto de resistencia en todo sentido, resistencia que acaso será negada por mucho tiempo más por la institución editorial y por un sector dela crítica literaria que aún no se ha encargado de hacer acordes con lo no occidental. En otras palabras, creemos que esta gran casa neobarroca escritura-mónada envuelve otra: casa neobarroca vida-muerte, donde ambas dimensiones se comunican y existen.

\footnotetext{
7 Paul Virilio define las prótesis tecnológicas como los elementos artificiales, cuya función es la
} de reemplazar o completar los órganos del cuerpo que fallan (C fr. Virilio, 1998: 12-13). 
Continúa este pliegue naturaleza-flora en el poema "Flores rústicas", en el quela percepción del afuera está dada por las intensidades de la sal via, el romero y el toronjil. Este poema destaca por el diálogo entre el sujeto textual y el niño, en el que la mama le enseña sobre dichas plantas, enseñanza en que el flujo perceptual va de una mónada o otra, mónadas semiabiertas que reciben el flujo del afuera. D estaca el flujo salvia por su desterritorialización entre los vegetales, correspondiendo a una macropercepción de la mónada, la que se produce aún con mayor intensidad en el poema "Salvia":

$$
\begin{aligned}
& \text { Esta siesta se la doy } \\
& \text { y ellas me la dan sobrada. } \\
& \text { Aunque les vuelvo sin bulto, } \\
& \text { mera señal, bizca fábula. } \\
& \text { ¿ ué bien que estamos así } \\
& \text { por el encuentro arrobadas! } \\
& \text { Sobran la ruta y las gentes } \\
& \text { y el tiempo que antes volaba }
\end{aligned}
$$

$\mathrm{H}$ ay dos aspectos a considerar en este poema: primero, que se escribe en el extranjero y movido por un pliegue de pensamiento que permite que $M$ istral participe del flujo salvia. Segundo, en el texto se produce un espacio perceptual que hace al sujeto (escritor) experimentar un afuera por medio del repliegue de escritura que registra la intensidad de la mónada y es en este espacio nuevamenteen donde se diluyela noción de tiempo y de cuerpo biológico. En el poema el sujeto "vuelve sin bulto", no hay materia, sólo mónada, sólo intensidad que en el encuentro enajena a los participantes: salvia y sujeto textual; y que los hace participar de un bloque temporal infinito, en donde sobra el tiempo que antes volaba - alusión a los poemas "M uro" y "Paraíso" de Tala: el primero, en relación a la idea detiempo en un mundo composible "terrenal", y el segundo, en lo que concierne al tiempo finito que quedó excluido por el umbral de este nuevo mundo composible. El niño, a su vez, es movido por otro tipo de flujo: un pliegue-sonidos canto de pájaros. Pliegue sobre pliegue, ondulaciones perceptuales y acústicas que proyectan esa curvatura, esa inflexión, ese movimiento de dirección, de fuerzas, de flujos de esa haecceidad montaña. Luego en el poema "M ontañas mías" se enuncia:

$$
\begin{aligned}
& \text { Y aunque me digan el mote } \\
& \text { de ausente y de renegada, } \\
& \text { me las tuve y me las tengo }
\end{aligned}
$$


y me sigue su mirada

(M istral, 1997: 74)

Continúa el pliegue de recuerdo y la posibilidad de hacer presente las curvaturas, las fuerzas de las montañas, "aunque me escuche la marcha", aunque esté recorriendo otro lugar geográfico. Agenciamiento de la montaña con M istral y, a su vez, de M istral con la montaña: devenir mujer de la montaña y montaña de la mujer. D evenir que permite a la mónada $\mathrm{M}$ istral resistir la muerte y "el exilio".

M istral dice en el poema "Cuco":

$$
\begin{aligned}
& \text { Ya no duermo bajo el árbol } \\
& \text { que tenga Cuco en las ramas } \\
& \text { ni el sol ni a la luna juegan } \\
& \text { conmigo las que jugaban. } \\
& \text { Burladas y burladoras } \\
& \text { en los trances de la danza. }
\end{aligned}
$$

Pero donde es $M$ ontegrande nunca se rompió la danza ni el Cuco falló a la cita en higuerales ni chacras, ¡ni a mí me faltó al dormir el Cuco de mis infancias

$$
\text { (M istral, 1997: 76) }
$$

Podemos distinguir dos tiempos: el del presente de la enunciación y el de lo evocado. En el primero nombra lo perdido, y en el segundo, ese afuera distante y "más lejano que toda forma de exterioridad" (D eleuze, 1987: 157), que por medio de la acción de pensar es plegado en el interior de la mónada, de manera queen la primera estrofa $M$ istral no tan sólo describe lo queya no tiene frente a sus ojos: bloqueárbol, Cuco, ramas, sol, luna, danza; sino más bien recupera esa potencia a través de la escritura en un pliegue de pasado que envuel ve el presente y que inclina hacia el futuro ese pliegue. D iario de vida, escritura de referentes biográficos que atrae ese afuera al presente de la enunciación. En el poema "Salvia" se da el mismo procedimiento: M istral transita por "Un campillo", haecceidad, y recupera sus pliegues: "el hálito de la menta / el ojo azul de la salvia, / el trascender del romero / y el pudor dela al bahaca (...)" (M istral, 1997: 77), destacando (nuevamente el flujo salvia) que "Toda hierba amé, pero ésta / siempre fue mi ahijada”. En otros poemas persiste este pliegue naturaleza-flora; 
en "H ierbas locas" se continúa con la retamilla, la malva, la topa-topa, la albahaca, el huilli, varila brava, flor de araña, amancai, la menta, todas aquellas plantas silvestres que no necesitan del cuidado humano para germinar y subsistir. Podemos entonces decir que de todas las plantas $M$ istral escoge aquellas que se agencian mejor con un territorio en donde el hombre no ha intervenido estriándolo. Se apropia de esos espacios lisos, nómades; de ahí que en Poema de C hile no se aludan a las personas y ciudades, o que cuando se mencionan sean para señalar su condición de estancadores de flujos: "es que me ahogan las casas. / O ye tú, cuando las hacen / desperdician las montañas" (M istral, 1997: 145). Luego $M$ istral vuelve a hacer un pliegue de memoria para asir ese afuera naturaleza, a través del acto de pensar recupera su huerta y agradece a D ios no tan sólo por las intensidades que se despliegan en ese territorio, sino también por el gozo que experimenta el reconocer que puede participar de los flujos de la $\mathrm{G}$ ea. M istral, al evocar su huerta, no tan sólo aprehende sus flujos, sino también su acción de alabanza hacia D ios:

$$
\begin{aligned}
& \text { Esta Patria que nos dieron } \\
& \text { apenas cría cizañas, } \\
& \text { gracias le daba al Señor } \\
& \text { por todo y por esta hazaña. } \\
& \text { Le agradecía la lluvia, } \\
& \text { el buen sol, la trebolada, } \\
& \text { la lluvia, la nieve, el viento } \\
& \text { norte que nos trae el agua. } \\
& \text { Le agradecía los pájaros, } \\
& \text { la piedra en que descansaba, } \\
& \text { y el regreso del buen tiempo. } \\
& \text { Todo lo llamaba gracia }
\end{aligned}
$$

(M istral, 1997: 86-87)

También M istral escoge para la producción de su casa neobarroca la relación hombre-tierra, la posibilidad de que el hombre cultive su ración de tierra, su huerta. Pero no cualquier persona se agencia con la tierra y puede gozar de ellas sus bondades o su gracia como señala M istral, sino sólo aquel que reconozca de igual a igual a estas criaturas, que tenga fe en sus poderes y que comprenda sus fuerzas avasalladoras. Pareciera ser que el conocimiento de ellas se da por experiencia y no por un cierto cientificismo escéptico. M istral dice:

Chiquillo, yo fui huertera.

Este amor me dio la mama.

Nos íbamos por el campo 


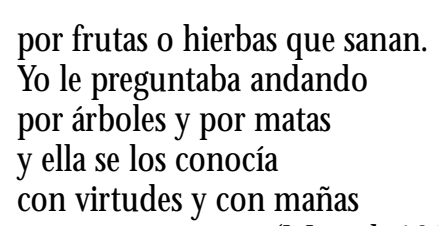

(M istral, 1997: 86)

$M$ istral recibe el conocimiento de la "hierbatera" de manera oral, es decir, ese saber pertenece a un conocimiento narrativ $0^{8}$, propio de la cultura de $M$ ontegrande. Ahora bien, la mama cumple también la función de hierbatera al narrarle los beneficios de las plantas al niño diaguita, como dice sobre la albahaca en este poema:

$$
\begin{aligned}
& \text { - Le oí decir a mi madre } \\
& \text { que la quería y plantaba } \\
& \text { la bebía en tisana, } \\
& \text { le oí decir que alivia } \\
& \text { el corazón y eran ciertas } \\
& \text { las cosas que me contaba }
\end{aligned}
$$

(M istral, 1997: 85).

Al respecto, es interesantela conexión que hace Patricia Pinto entre la denominación del sujeto textual "la mama" y el concepto de mama, al situarla como la Pacha-M ama, la Gran M adre (Cfr. Pinto, 1989: 30).

En este mismo poema, también M istral señala que "pasan por la huerta de Lucía", destacando al ingresar su nombre cívico que se reconoce como sujeto textual de este poema.

Por otra parte, aparece como referente histórico la reforma agraria, según ha sido señalado por la crítica, y frente a la problemática de la reforma agraria, M istral manifiesta su posición en favor, incluso su enunciación en Poema de C hilecomo una profecía: su aprobación. Esta reflexión se aborda en varios poe mas: "Flores rústicas", "M anzanos", "Campesinos", "Reparto de la tierra", "¿A dóndees quetú mellevas?". Junto con el tema de la reforma agraria aparece otro componente político en la escritura mistraliana: el reconocimiento al pueblo indígena. Este aspecto no tan sólo es desarrollado en al gunos poemas específicos, sino también a partir de la condición misma del receptor del texto: el niño diaguita.

\footnotetext{
${ }^{8}$ La noción de conocimi ento narrativo la extraemos de J ean-François Lyotard, quien lo emplea
} para referirse a un conocimiento no científico (C fr. Lyotard, 1987). 
Retomando los pliegues que se producen en Poema de Chile en "Eres uno caminando", se profetiza sobre los pliegues que hará la mónada Gabriela y que afectarán a la mónada niño diaguita, porque serán acciones que irán de una singularidad a otra:

\author{
Te haré cantar a la alondra \\ porque no escuches la rana; \\ te enseñaré a deletrear \\ la callada vía láctea,

Todos estos pliegues resisten a la muerte, a través del agenciamiento con la tierra - que en el poema se evidencia por el cantar de la alondra y del universo (deletrear la vía láctea) ${ }^{9}$ y la producción de un tipo de relación con el afuera: el pensamiento. Luego, en el poema, el niño le pregunta ala mama por su nombre y ella responde:

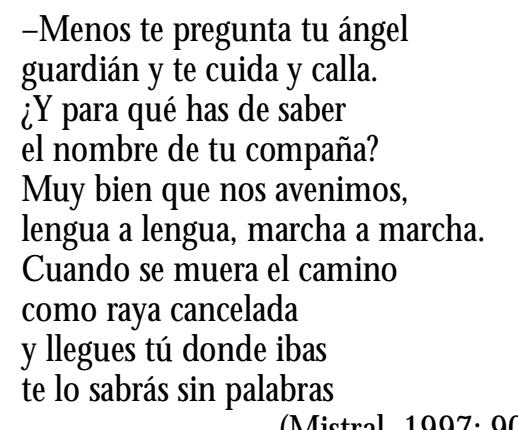

Se puede apreciar cómo la respuesta de la mama no satisface a la pregunta sobre su nombre, se niega a producir un enunciado, un saber sobre sí misma anteel otro y, en cambio, proponeun nuevo tipo de relación: queel niño descubra cómo llamarla. Propone entonces un conocimiento que es un no-conocimiento, por cuanto no es un saber, sino más bien un afuera: la intensidad del nombre. Se invita al niño a relacionarse con el afuera, hacer un pliegue del afuera por medio del pensamiento, de la intensidad desprendida de Un-Andarla-G ea en compañía de esta mama fantasma.

${ }^{9} \mathrm{M}$ istral desarrolla la relación con el universo, su conocimiento, en el poema denominado "Constelaciones". 
M istral, producto de su cargo político o de su oficio de escritor, recorría América y Europa, y se sentía nómada: "ya voy tomando no sé qué carnez de judío errante" (Q uezada, 2002: 102), pero veía que esa condición era, tal vez, imposible de sobrellevar, no en lo concerniente a la constante muda de casa, sino más bien porque ello implicaba, en muchas ocasiones, tener un hogar rodeado de ruidosa civilización ${ }^{10}$. Buscaba, entonces, una fuga, un agenciamiento con la naturaleza. D e esta manera, donde fuera procuraba otorgarse un contacto con lo fluido de la flora, ya sea labrando la tierra, haciendo un jardín, o escribiendo; y es en la escritura, a través del pensamiento, de la memoria, en dondeese afuera se hace interior, deviene estrategia de resistencia ante "el olvido del olvido": la muerte.

\section{BIBLIO GRAFIA}

\section{a) Bibliografía de $\mathrm{G}$ abriela M istral:}

M istral, Gabriela. 1953. Tala. Buenos Aires: Ed. Losada S. A.

- - - - . 1967. Poema deChile(Edición de D oris $D$ ana). Barcelona: Ed. Pomaire. - - - - . 1985. Poema de Chile (Revisión, ordenación y prólogo de Jaime Q uezada). Santiago Chile: Ed. Seix Barral.

----1 . 1989. Lagar. Santiago de Chile: Ed. Andrés Bello.

- - - - . 1997. Poema Chile(Revisión, ordenación y prólogo de Jaime Q uezada). Santiago Chile: Ed. Universitaria.

- - - - . 1999. Recados para hoy y mañana. Textosinéditos. Tomo I. (Compilación de Luis Vargas Saavedra). Santiago Chile, Ed. Sudamericana:

\section{b) Bibliografía sobre G abriela M istral:}

Daydí-Tolson, Santiago. 1969. "Gabriela M istral y su Poema de Chile". En: Revista Signos. Val paraíso, Tomo III, N os 1-2, enero-diciembre, pp. 147-151.

-----1 1982. "El yo lírico en Poema de Chile, de Gabriela M istral". En: Revista Chilena de Literatura $\mathrm{N} \cong 19$, abril, pp. 5-20.

- - - - . 1983. "La locura en Gabriela M istral". En: Revista Chilena de Literatura $\mathrm{N} \cong 21$, abril, pp. 47-62.

${ }^{10}$ En la siguiente cita queda de manifiesto la percepción que M istral tenía sobre las ciudades rurales: "D uermo, hace diez años tal vez, en las pobres casas ciudadanas y no puedo todavía al despertarme aceptar sin repulsión física violenta los ruidos sin nobleza de municipal y bajísimo ajetreo, batahola formada por camiones, sirenas; tártaras (las de grato sillbo son pocas), de avalancha detrenes einterjecciones de mercado; todo lo cual se me entre por el cuadrado ocioso de la ventana o la puerta y me avienta de la cara la maravilla del sueño matinal, parada todavía en mi cara" (Q uezada, 2002: 26-27). 
- - - - - . 1986. "Las patrias de G abriela M istral". En: Revista Chilena de Lite ratura. $N$ os 27-28, abril-noviembre. Santiago Chile.

Falabella, M aría Soledad. 1994. "'¿Q ué será de C hile en el cielo?' U na propuesta para el Poema de Chile de Gabriela M istral". Proyecto de tesis para optar al grado de Licenciado en H umanidades con mención en Lengua y Literatura. Universidad de Chile. Facultad de Filosofía y H umanidades.

------ 1997. "D esierto: territorio, desplazamiento y nostalgia en Poema de Chile, de G abriela M istral". En: Revista Chilena de Literatura N 50, abril, pp. 7996.

O elker, D ieter. 1989. "G abriela M istral: Poesía enigmática/poesía dialéctica”. En: Acta Literaria N 014 , pp. 95-107.

Pinto, Patricia. 1989. "La mujer en Poema deC hile: Entreel decir y el hacer de G abriela". En: Acta Literaria $\mathrm{N} 014$, pp. 25-43.

Q uezada, Jaime. 2002: Bendita mi lengua sea. D iario íntimo de Gabriela M istral. Santiago Chile: Editorial Planeta.

Rojo, Grínor. 1997. Dirán que esá en la gloria... (M istral). Santiago Chile: Fondo de Cultura Económica.

\section{c) Bibliografía crítica}

Blanchot, M aurice. 1969. El espacio literario. Buenos Aires: Editorial Paidós (1a ed. francesa: 1955).

D eleuze, Gilles. 1987. Foucault (Prólogo de M iguel M orey). BuenosAires: Ed. Paidós. (1 1 ed. francesa: 1986).

----- . 1989. El pliegue. Leibniz y el barroco. M adrid: Ed. Paidós. (1a ed. francesa: 1988).

D eleuze, Gilles y G uattari, Félix. 1978. Kafka, por una literatura menor. M éxico: Ed. Era S.A. (1 $\underline{a}$ ed. francesa: 1975).

------- . 1995. El anti-Edipo. M adrid: Ed. Paidós (1ạ ed. francesa: 1972).

- - - - - - 1997. M il mesetas. Valencia: Ed. Pre-Textos (1ª ed. francesa: 1980).

------.2001 . ¿Q uéesla filosofía? Barcelona: Ed. Anagrama (1a ed. francesa: 1991).

Lyotard, J ean François. 1987. La posmodernidad (explicada a losniños). Barcelona: Ed. Gedisa.

Sarduy, Severo. 1987. Ensayos generales sobre el barroco. Buenos Aires: Ed. Fondo de Cultura Económica.

Virilio, Paul. 1998. Estética de la desaparición. Barcelona: Ed. Anagrama (1ª ed. francesa: 1980). 